\title{
Ex vivo whole-embryo culture of caspase-8-deficient embryos normalize their aberrant phenotypes in the developing neural tube and heart
}

K Sakamaki ${ }^{\star, 1}$, T Inoue ${ }^{2}$, M Asano ${ }^{3,7}$, K Sudo $^{3}$, H Kazama ${ }^{1}$, J Sakagami ${ }^{3}$, S Sakata ${ }^{1}$, M Ozaki ${ }^{4}$, S Nakamura ${ }^{2}$, S Toyokuni ${ }^{5}, \mathrm{~N}$ Osumi ${ }^{6}$, Y Iwakura ${ }^{3}$ and $S$ Yonehara ${ }^{\star, 1}$

${ }^{1}$ Graduate School of Biostudies and Institute for Virus Research, Kyoto University, Sakyo-ku, Kyoto 606-8507, Japan

2 Division of Biochemistry and Cell Biology, National Institute of Neuroscience, National Center of Neurology and Psychiatry, Kodaira 187-8502, Japan

${ }^{3}$ Center for Experimental Medicine, Institute of Medical Science, University of Tokyo, Minato-ku, Tokyo 108-8639, Japan

${ }^{4}$ Laboratory for Neural Architecture, Brain Science Institute, The Institute of Physical and Chemical Research, RIKEN, Wako 351-0198, Japan

5 Department of Pathology and Biology of Diseases, Graduate School of Medicine, Kyoto University, Sakyo-ku, Kyoto 606-8501, Japan

${ }^{6}$ Department of Developmental Neurobiology, Graduate School of Medicine, Tohoku University, Aoba-ku, Sendai 980-8575, Japan

7 Present address: Institute for Experimental Animals, Graduate School of Medicine, Kanazawa University, Kanazawa 920-8640, Japan

* Corresponding authors: K Sakamaki, Shogoin-Kawaramachi 53, Sakyo-ku, Kyoto 606-8507, Japan. Tel.: 81-75-751-4786; Fax: 81-75-751-4784; E-mail: ksakamak@virus.kyoto-u.ac.jp and S Yonehara, ShogoinKawaramachi 53, Sakyo-ku, Kyoto 606-8507, Japan. Tel.: 81-75-751-4783; Fax: 81-75-751-4784; E-mail: syonehar@virus.kyoto-u.ac.jp

Received 20.3.02; revised 6.4.02; accepted 7.6.02 Edited by $\mathrm{H}$ Ichijo

\begin{abstract}
Caspase-8 plays the role of initiator in the caspase cascade and is a key molecule in death receptor-induced apoptotic pathways. To investigate the physiological roles of caspase-8 in vivo, we have generated caspase-8-deficient mice by gene targeting. The first signs of abnormality in homozygous mutant embryos were observed in extraembryonic tissue, the yolk sac. By embryonic day (E) 10.5, the yolk sac vasculature had begun to form inappropriately, and subsequently the mutant embryos displayed a variety of defects in the developing heart and neural tube. As a result, all mutant embryos died at E11.5. Importantly, homozygous mutant neural and heart defects were rescued by ex vivo wholeembryo culture during E10.5-E11.5, suggesting that these defects are most likely secondary to a lack of physiological caspase- 8 activity. Taken together, these results suggest that caspase-8 is indispensable for embryonic development.

Cell Death and Differentiation (2002) 9, 1196-1206. doi:10.1038/sj.cdd. 4401090
\end{abstract}

Keywords: caspase-8; apoptosis; hemorrhage; cardiac rupture; angiogenesis; whole-embryo culture

\begin{abstract}
Abbreviations: ES, embryonic stem; FADD, Fas-associated death domain protein; MEF, mouse embryonic fibroblasts; PBS, phosphate-buffered saline; PECAM-1, platelet endothelial cell adhesion molecule-1; PFA, parafolmaldehyde; RT-PCR, reverse-transcriptase and polymerase chain reaction; TUNEL, terminal deoxynucleotidyl transferase-mediated dUTP-digoxigenin nick-end labeling
\end{abstract}

\section{Introduction}

Apoptosis, or programmed cell death, is the principal mechanism utilized by multicellular organisms to orchestrate tissue morphogenesis during development and maintain homeostasis in adulthood. ${ }^{1-3}$ Apoptosis also occurs during defense processes and immune responses. ${ }^{4}$ Studies on signal transduction mechanisms in apoptosis identified several molecules which effect and regulate this process. Of these molecules, caspases, a family of cysteine proteases, have been shown to act as the executioners of apoptosis. ${ }^{5}$ In mammals, fourteen caspases have been identified, most of which are activated during apoptosis. Among these, caspase8 (also known as FLICE/MACH/Mch5) is an initiator caspase with a long prodomain, termed a 'death effector domain' (DED), which activates downstream effector caspases (e.g. caspase- $3,-6$ and -7$).{ }^{6,7}$ It has been shown that caspase- 8 is essential for Fas-mediated apoptotic signaling. ${ }^{8,9}$ Ligation of Fas results in the recruitment of caspase-8 via interaction with the adapter molecule FADD (Fas-associated death domain protein, also called MORT1). Recruitment of caspase- 8 to the complex initiates autoprocessing of procaspase-8 to an active form which is released into the cytoplasm. ${ }^{10}$ Activated caspase-8 cleaves and activates downstream caspases, thereby committing the cell to apoptosis. Caspase-8 also activates another apoptotic pathway, which, through processing of Bid, mediates release of cytochrome $c$ from mitochondria and activation of caspase-9. ${ }^{11}$ And, in addition to Fas, caspase-8 is involved in apoptotic signaling via other death receptors, such as tumor necrosis factor receptor type 1 (TNFR1), death receptor 3 (DR3) and TNF-related apoptosisinducing ligand (TRAIL) receptors. ${ }^{12-15}$ Clearly, caspase-8 is an important mediator for a wide range of apoptotic pathways.

During embryogenesis, apoptosis is utilized ubiquitously to eliminate unwanted or excess cells in the organism. Recently, the targeted disruption of several genes involved in apoptosis has been performed. ${ }^{16,17}$ Among those analyzed, it has been shown that caspase-3, caspase-9 and Apaf-1 are involved in brain development during late embryogenesis. ${ }^{18-22}$ Targeted disruption of mouse FADD results in developmental heart abnormalities and embryonic lethality. ${ }^{23,24}$ Furthermore, caspase-8-deficient mice display impaired heart muscle development and accumulation of 
erythrocytes in the liver. ${ }^{12}$ More recently, it has been reported that Casper (also called c-FLIP), which negatively regulates Fas-mediated apoptosis by interacting with FADD or/and caspase-8, is also involved in heart development during embryogenesis. ${ }^{25}$ Taken together, evidence from FADD-, Casper- and caspase-8-deficient mice suggests that these molecules function in a Fas-independent manner during embryogenesis.

To investigate the biological function of caspase-8 in vivo, we generated mutant mice devoid of proteolytic function by targeted disruption of the protease domain using homologous recombination. Like the previous report on this knockout model, ${ }^{12}$ we found that protease-deficient caspase-8 mutants die in utero and exhibit cardiac rupture. Moreover, we report the new finding of several additional embryonic and extraembryonic defects which arise during embryogenesis. We also report that our caspase-8 mutant embryos could be rescued by ex vivo whole-embryo culture, a finding which could help point to an explanation of the defects displayed by our mice. The present study suggests first the direct involvement of caspase-8 in early mouse embryonic development, particularly in organogenesis.

\section{Results}

\section{Embryonic expression of caspase-8}

In a previous study, we demonstrated that caspase-8 is expressed in adult tissues as well as in embryos at 9.5 days (E9.5) and 17 days (E17) of development by Northern blot analysis. $^{26}$ To confirm these findings, we further analyzed caspase-8 expression in embryos at the protein level (Figure 1). We prepared cell lysates from E8.5 embryos and from various tissues of E17 embryos and analyzed them by immunoblotting with an anti-mouse caspase- 8 monoclonal antibody. As a positive control, we used cell lysates from JB-6 stable transfectants expressing mouse caspase-8. We detected a $55-\mathrm{kDa}$ protein in JB-6 transfectants, but not in parental JB-6 cells lacking endogenous caspase-8 (Figure 1, lanes 14 and 15). Similarly, we observed a strong band of the same size in E8.5 embryos and in the thymus, skin and muscle of E17

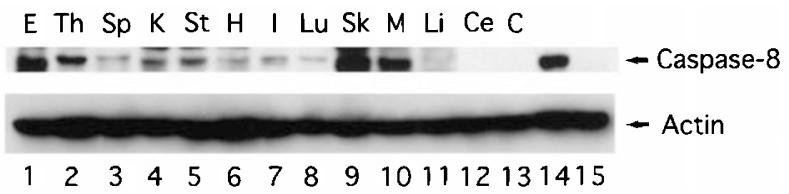

Figure 1 Immunoblot analysis of caspase-8 in mouse embryos. Approximately $70 \mu \mathrm{g}$ of cell lysates from E8.5 embryos (lane 1) and from various E17 embryonic tissues (lanes 2-13) were analyzed by SDS-PAGE followed by immunoblotting with anti-mouse caspase- 8 antibody. Cell lysates from JB-6 transfectants expressing mouse caspase- 8 and from parental JB- 6 cells were also analyzed (lanes 14 and 15). Blots were also probed with anti-actin antibody as a standard control. Abbreviations: E, E8.5 embryo; Th, thymus; $\mathrm{Sp}$, spleen; K, kidney; St, stomach; $\mathrm{H}$, heart; I, intestine; Lu, lung; Sk, skin; M, muscle; Li, liver; $\mathrm{Ce}$, cerebrum; $\mathrm{C}$, cerebellum embryos (Figure 1, lanes 1, 2, 9 and 10). A faint band was observed in cell lysates from the spleen, kidney, stomach, heart, intestine and lung (lanes 3-8). Caspase-8 could not be detected in the liver and brain (Figure 1, lanes 11-13). Taken together, these data strongly suggest that caspase-8 is expressed in several tissues during mouse embryogenesis, at least between E8.5 and E17. To help determine the role played by caspase- 8 during this period, we created caspase- 8 knockout mice by targeted disruption.

\section{Targeted disruption of the mouse caspase- 8 gene and generation of caspase-8 knockout mice}

Caspase-10 (also known as FLICE2/Mch4), a caspase-8 homologue, plays a similar role to caspase-8 in Fas-mediated apoptotic signaling in humans, ${ }^{27}$ and it was thought that caspase-10 might compensate for the lack of caspase-8 activity in caspase-8-null mice. We speculated that a truncated caspase- 8 protein lacking the protease domain might act as a dominant-negative molecule and inhibit the function of caspase-10. To generate this caspase-8 mutant, we designed a targeting vector by which a stop codon and SV40 polyadenylation sequence would be inserted into exon 7 of the caspase-8 gene (Figure 2A). After transfection of the targeting vector and selection with $\mathrm{G} 418$, four homologous recombinant embryonic stem (ES) clones were isolated (Figure 2B), two of which were used to produce chimeric mice. Finally, we established independent lines of caspase-8 knockout mice from six chimerae and examined their progenies.

\section{Embryonic lethality of homozygous caspase-8-deficient mice}

The established heterozygous mutants displayed normal phenotype and retained propagative activity. However, no homozygous mutants were observed among live pups genotyped from heterozygous mating, indicating that homozygous mutants are embryonic lethal. Therefore, we examined embryos of various stages (Table 1), and found that until E10.5, homozygous mutant embryos were detected in the expected Mendelian ratio (25\%). However, all homozygous mutants obtained at later timepoints (E11.5 to E14.5) died accompanying with abnormal phenotypes. Most homozygous mutant embryos displayed signs of abdominal hemorrhage (described below in detail). This phenotype, observed in all of our mutant lines, was similar to that of caspase-8 null-mutant mice. ${ }^{12}$ However, by reverse-transcriptase and polymerase chain reaction (RT-PCR) analysis of embryonic transcripts, we were able to detect truncated caspase-8 mRNA transcribed from the mutant allele (Figure $2 \mathrm{C}$ ). Furthermore, by immunoblot analysis with an anti-caspase- 8 antibody, a $55-\mathrm{kDa}$ pro-caspase-8 was detected in wild-type mouse embryonic fibroblasts (MEFs), but not in homozygous mutant MEFs, whereas a peptide at $25 \mathrm{kDa}$ corresponding to the DED domains of caspase-8 was observed in mutant MEFs (Figure 2D). These results suggest that our mice exhibit protease-deficient mutation, but not null-mutation, of the caspase-8 gene. We designate our homozygous mutant mice as caspase $-8^{D E D / D E D}$. 


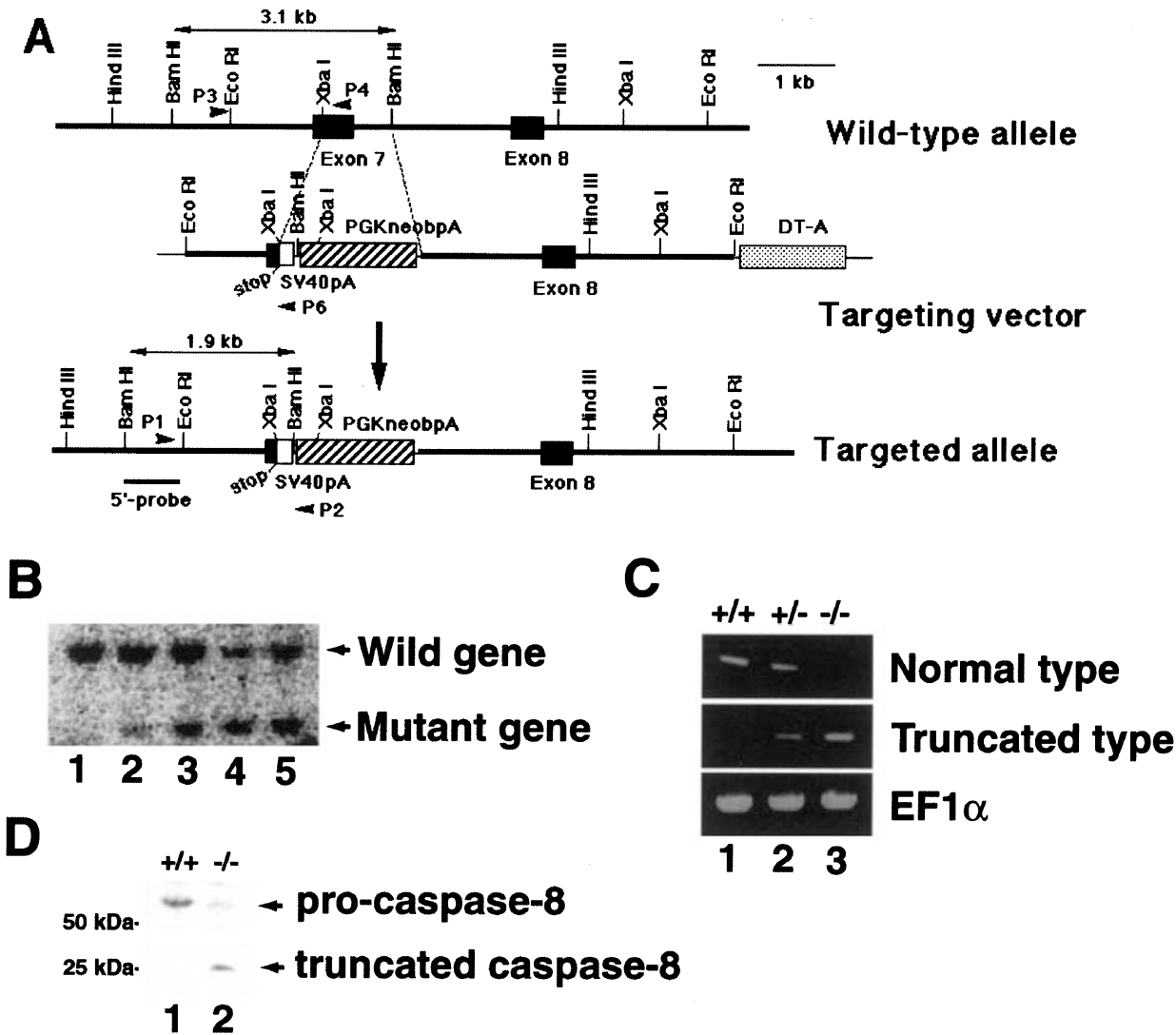

Figure 2 Targeted disruption of the mouse caspase-8 gene by homologous recombination. (A) Targeting strategy for homologous recombination. Exons of the caspase-8 gene are depicted as closed boxes. The SV40 polyA sequence, the PGKneobpA cassette and the diphtheria toxin A fragment gene (DT-A) cassette are indicated by open, hatched and dotted boxes, respectively. Primers (P1, P2, P3, P4 and P6) used for screening and RT-PCR are shown by arrowheads. A 5'-probe for Southern hybridization and DNA fragments expected after BamHI digestion are indicated by a bold line and arrows, respectively. (B) Southern blot analysis of ES cell clones. Genomic DNAs isolated from parental cells (lane 1) and ES clones (lanes 2-5) were digested with BamHI, resolved by electrophoresis and hybridized with a 5'-probe. The $3.1 \mathrm{~kb}$ and $1.9 \mathrm{~kb}$ DNA bands correspond to the wild-type and mutant genes, respectively. (C) RT-PCR analysis of caspase-8deficient embryos. Total RNAs from E10.5 embryos obtained by crossing heterozygotic mice were amplified as described in Materials and Methods. PCR products derived from wild-type embryo (lane 1) and heterozygous (lane 2) and homozygous (lane 3) mutant embryos were analyzed by electrophoresis for detection of normal (top) and truncated (middle) caspase-8 transcripts. Primers for mouse EF1 $\alpha$ transcripts were used as a standard control (bottom). (D) Immunoblot analysis of MEFs. Cell lysates of wild-type $(+/+)$ and homozygous caspase-8 mutant $(-/-)$ MEF cells were analyzed by SDS -PAGE followed by immunoblotting with antimouse caspase-8 monoclonal antibody specific to the DED domain of caspase-8. Size standards are shown on the left side

Table 1 Genotyping of mice derived from caspase-8 heterozygous intercrosses

No. of abnormal $-I-$

\begin{tabular}{|c|c|c|c|c|}
\hline \multirow{2}{*}{$\begin{array}{l}\text { Age } \\
\text { (days) }\end{array}$} & \multicolumn{3}{|c|}{ No. of genotypes (\%) } & \multirow{2}{*}{$\begin{array}{c}\text { homozygotes }^{\text {a }} \\
(\%)\end{array}$} \\
\hline & $+/+$ & $+1-$ & $-I-$ & \\
\hline P21-28 & $22(30)$ & $51(70)$ & $0(0)$ & \\
\hline E14.5- & $48(36)$ & $71(53)$ & 15 (11) & $15 / 15(100)$ \\
\hline E12.5 & $18(32)$ & $31(58)$ & $6(10)$ & $6 / 6(100)$ \\
\hline E11.5 & $48(27)$ & $100(60)$ & 24 (13) & $24 / 24(100)$ \\
\hline E10.5 & 72 (33) & $87(42)$ & $54(25)$ & $3 / 54(6)$ \\
\hline E9.5 & $16(34)$ & $21(46)$ & $9(20)$ & $0 / 9(0)$ \\
\hline E8.5 & $6(37)$ & $8(50)$ & $2(13)$ & $0 / 2(0)$ \\
\hline
\end{tabular}

The genotype of mice at indicated postnatal $(P)$ or embryonic $(E)$ days were

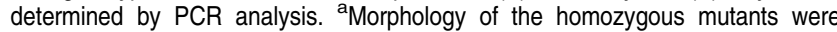
judged under the microscope.

\section{Extraembryonic defects in caspase- $8^{D E D / D E D}$ mutant embryos}

Abnormal development of caspase- $8^{D E D / D E D}$ mutant mice was first observed in the extraembryonic tissue, the yolk sac. The yolk sac of the $\mathrm{E} 11.5$ caspase- $8^{D E D / D E D}$ mouse appears pale and displays underdeveloped vasculature (Figure $3 \mathrm{~A}$ ). To analyze these defects, we examined the yolk sac vascular endothelium using an antibody specific for platelet endothelial cell adhesion molecule-1 (PECAM-1/CD31) (Figure 3B). In wild-type yolk sacs, the vascular network was pruned and remodeled to form a branched and intricate tree-like network between $\mathrm{E} 9.5$ and $\mathrm{E} 11.5$. In contrast, caspase-8 $8^{D E D / D E D}$ yolk sacs still exhibited the honeycomb-like primary capillary plexus at E10.5. Eventually, regression of vessels was observed in the E11.5 mutant yolk sac. Upon histological 

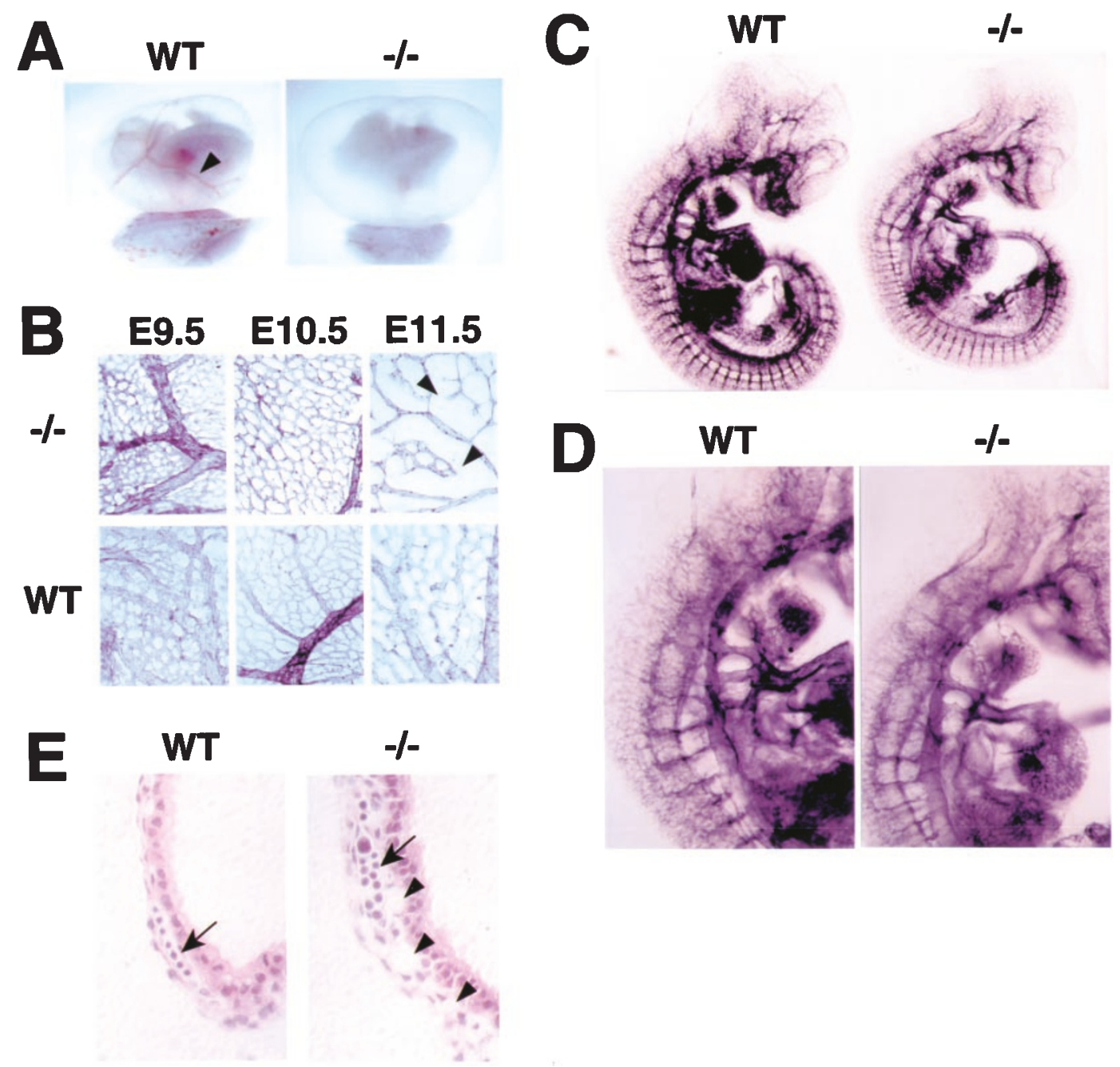

Figure 3 Yolk sac defects in caspase-8-deficient embryos. (A) Morphology of yolk sacs from E11.5 wild-type (left) and caspase-8 ${ }^{D E D / D E D}$ (right) embryos. Large vitelline blood vessels (shown by an arrowhead) are clearly observed in the wild-type, but not the caspase- $8^{D E D / D E D}$, yolk sac. (B) Whole-mount immunohistochemistry of yolk sacs dissected from wild-type (bottom) and caspase-8 $8^{D E D / D E D}$ (top) embryos. Yolk sacs prepared at E9.5 (left), E10.5 (middle) and E11.5 (right) were immunostained with an anti-PECAM-1 antibody. Regressive vessels are indicated by arrowheads. (C and D) Whole-mount immunostaining of E10.5 wild-type (left) and caspase- $8^{D E D / D E D}$ (right) embryos. Embryos proper were immunostained with anti-PECAM-1 antibody as described in Materials and Methods. (E) Histological analysis of yolk sacs dissected from wild-type (left) and caspase-8 ${ }^{D E D / D E D}$ (right) embryos at E11.5. Yolk sac sections were stained with hematoxylin and eosin. A vessel containing blood cells and a vessel lacking blood cells are shown by an arrow and an arrowhead, respectively. Blood cells were detected in only a few vessels of each E11.5 mutant yolk sac. Abbreviations: WT, wild-type; $-/-$, caspase-8DED/DED

analysis of the vasculature, it was readily apparent that $\mathrm{E} 11.5$ mutant vessels contained far fewer blood cells than vessels of wild-type yolk sacs (Figure $3 \mathrm{E}$ ). These results indicate that caspase- 8 is necessary for normal maturation of the yolk sac primary capillary plexus into the more mature tree-like hierarchy of vessels, and probably for development of blood cells.

On the other hand, whole-mount immunostaining of E10.5 embryos with anti-PECAM-1 antibody revealed no differences between the vascular systems of wild-type and caspase- $8^{D E D / D E D}$ embryos proper (Figure 3C, D). A similar branched network of blood vessels was observed in both wild-type and mutant embryos. These results indicate that caspase-8 activation is required for angiogenesis only in the extraembryonic yolk sac.

\section{Cardiac rupture in caspase- $8^{D E D / D E D}$ mutant embryos}

To learn more about the defects in caspase $-8^{D E D / D E D}$ embryos associated with abdominal hemorrhage, detailed histological analyses were performed on E10.5-11.5 embryos. As shown in Figure $4 \mathrm{~A}$ and $\mathrm{B}$, we confirmed that the abdominal hemorrhage was the result of an efflux of blood cells into the pericardial cavity, and that the main muscular framework of the heart had undergone lysis. By terminal 

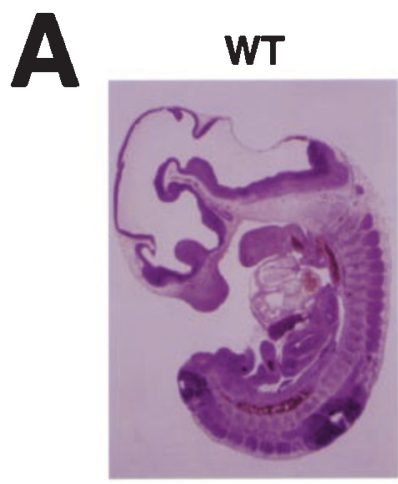

B
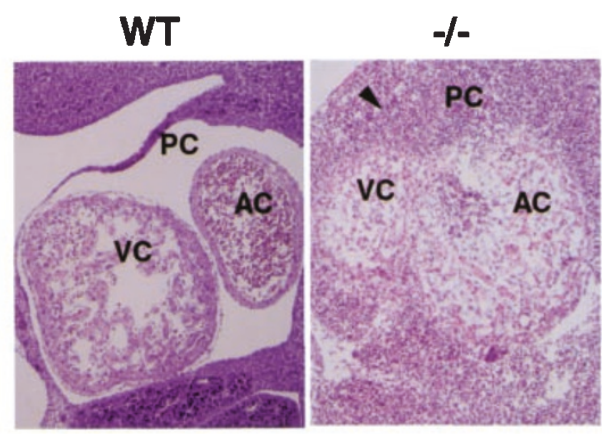

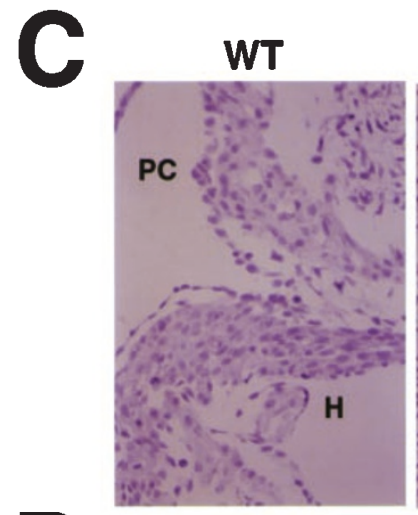

D
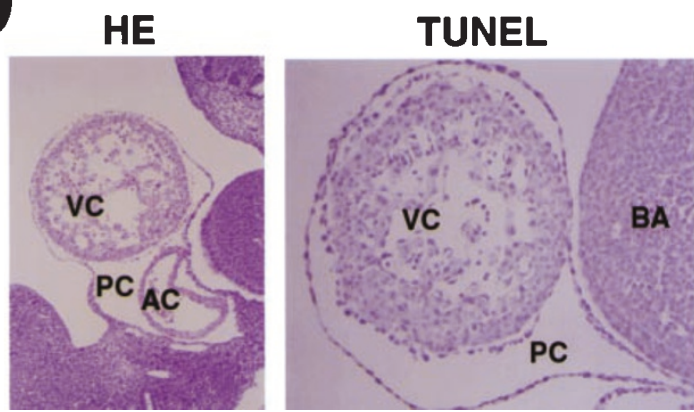

Figure 4 Histological analysis of heart tissue from caspase-8-deficient mice. (A and $\mathbf{B}$ ) Hematoxylin and eosin (HE) staining of sagittal sections of E11.5 wild-type (left) and caspase- $8^{D E D / D E D}$ (right) embryos. Hemorrhage is shown by arrowheads in photographs of whole body (A) and pericardial cavity and heart (B). The arrow shows the neural tube, which developed irregularly, in the caspase- $8^{D E D / D E D}$ embryo. (C) TUNEL staining of hearts from E11.5 wild-type (left) and caspase$8^{D E D / D E D}$ (right) embryos. TUNEL-positive cells (colored brown) are apoptotic. (D) HE and TUNEL staining of the E10.5 caspase-8 sections were stained with hematoxylin and eosin (left) and analyzed by TUNEL staining (right). No TUNEL-positive cells were observed in the caspase-8 ${ }^{D E D / D E D}$ heart. Abbreviations: WT, wild-type; $-/-$, caspase- $8^{D E D / D E D} ; \mathrm{H}$, heart; PC, pericardial cavity; AC, atrial chamber; VC, ventricular chamber; BA, branchial arch

deoxynucleotidyl transferase-mediated dUTP-digoxigenin nick-end labeling (TUNEL) staining of caspase-8DED/DED E11.5 embryos, we found that the lytic change was due to apoptosis of cardiomyocytes (Figure 4C). Interestingly, neither cardiac rupture nor cardiomyocyte apoptosis was observed at E10.5 (Figure 4D). In addition, no apoptosis was observed in E11.5 caspase-8 $8^{D E D / D E D}$ embryos in tissues other than the heart (data not shown). Thus, it appears that this malformation event occurs during heart development between E10.5 and E11.5, subsequent to the appearance of yolk sac defects. We assume that cardiac rupture secondary to cardiomyocyte apoptosis is the major reason for embryonic lethality in caspase-8-deficient mice.

\section{Neural tube defects in caspase- $8^{\text {DED/DED }}$ mutant embryos}

Another aberrant phenotype observed in the mutants was a defect in the neural tube. As shown in Figure $5 \mathrm{~A}$, the neural tubes of E11.5 caspase-8 $8^{D E D / D E D}$ embryos displayed a kinklike irregular pattern as compared with E10.5 embryos. These observations were confirmed by histological analysis (Figure 4). To further analyze the neural tube defect, we examined the expression of neurogenic and neuronal markers by in situ hybridization and immunohistochemical analyses (Figure
$5 \mathrm{~B}-\mathrm{E})$. Although caspase- $8^{D E D / D E D}$ and wild-type embryos exhibited similar expression patterns at E10.5, the former exhibited altered patterns by E11.5. The ventricular zone became narrower in the mutant, and expression of neurogenic cell markers in that region (Pax6, Mash1 and Neurogenin-2) was diminished relative to the wild-type. In addition, though some neuronal proteins ( $\beta$-tubulin, neurofilament, and Islet-1) remained at wild-type levels, transcripts of other neuronal markers (Islet-2, Chox-10, En1, and Evx1) disappeared or were dramatically reduced in the mutant neural tube. Surprisingly, we were unable to detect massive apoptotic cells in the neural tube of mutant embryos (data not shown), in contrast with their prominence in the heart (Figure 4C). Based on these observations, we conclude that loss of function of caspase-8 affects neural tube development between E10.5 and E11.5.

\section{Rescue of caspase- $8^{D E D / D E D}$ mutant phenotypes in whole-embryo culture}

It is difficult to distinguish whether the abnormal cardiomyocyte apoptosis is a direct result of caspase-8-deficiency or a secondary effect of cells lacking the physiological action of caspase-8. To understand the effect of the caspase-8deficiency in the heart, we performed whole-embryo culture 


\section{A}

E11.5 E10.5 E11.5(WEC)
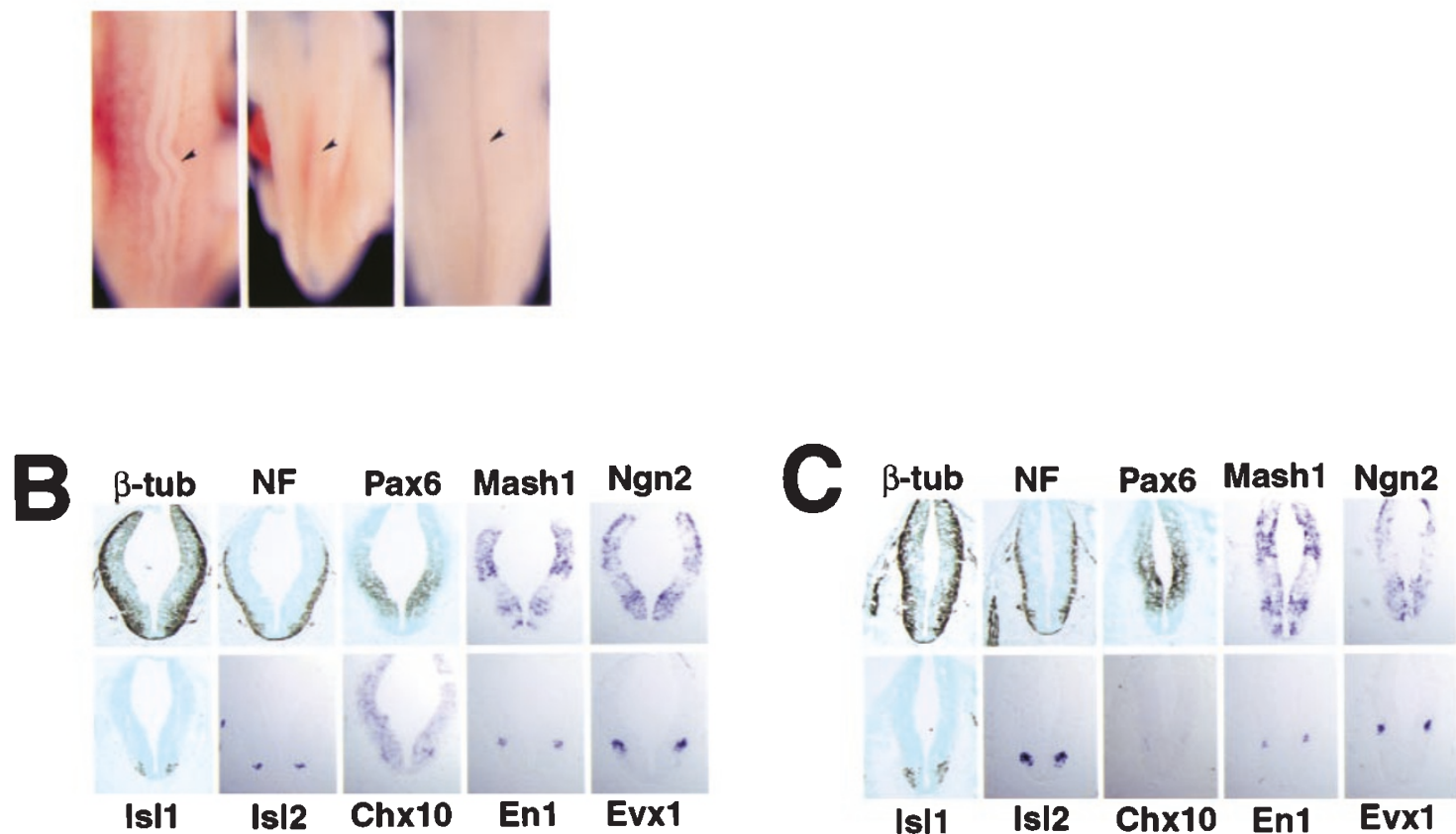

D
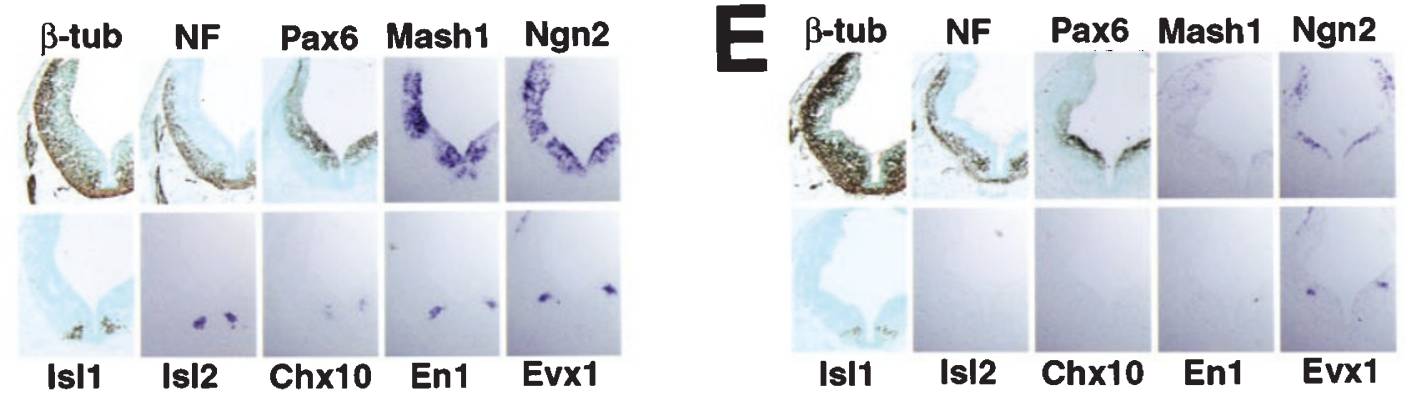

Figure 5 Morphological and neuron-specific gene expression analyses of the caspase-8-deficient neural tube. (A) Morphology of the neural tubes in caspase$8^{D E D / D E D}$ embryos. Neural tube kinks were observed in the embryo dissected at E11.5 (left), but not at E10.5 (middle) or in E11.5 embryo after whole-embryo culture (WEC) (right). Neural tubes are indicated by arrowheads. (B-E) Immunohistochemistry and in situ hybridization of neural tubes from wild-type (B and $\mathbf{D}$ ) and caspase-8 $8^{D E I D E D}(\mathbf{C}$ and $\mathbf{E})$ embryos. Transverse sections of hindbrain neural tube prepared at E10.5 (B and $\left.\mathbf{C}\right)$ and $\mathbf{E} 11.5$ (D and $\left.\mathbf{E}\right)$ were examined with antibodies against $\beta$-tubulin ( $\beta$-tub), neurofilament (NF), Pax6 and Islet-1 (Isl1) and with RNA probes for Islet-2 (Isl2), Chox-10 (Chx10), En1, Evx1, Mash1 and Neurogenin-2 (Ngn2) as described in Materials and Methods

of caspase-8 $8^{D E D / D E D}$ mutant embryos and their littermates during E10.5-E11.5. It has been shown that this wholeembryo culture system mimics the in vivo situation during E8$\mathrm{E} 12 .^{28}$ If caspase-8-deficiency acts in a cell-autonomous manner in cardiomyocytes, the mutant phenotype would be reproducible by ex vivo culture. Unexpectedly, cardiac rupture was no longer observed in caspase- $8^{D E D / D E D}$ embryos after 24 hours cultivation, which grew as well as wild-type embryos from $34-38$ somites to $45-50$ somites comparable to E11.5 normal embryos in vivo (Figure 6A). Histological analysis of cultured caspase- $8^{D E D / D E D}$ embryos also showed normal heart development (Figure 6B). Myocardial trabeculation developed normally in caspase $-8^{D E D / D E D}$ hearts during culture. In addition, apoptotic myocytes were not observed in the heart by TUNEL staining, although a few apoptotic cells were detected in other tissues including the midgut. These results indicate that caspase-8 is not directly involved in myocyte survival by itself, and we emphasize that the heart defect occurs as a secondary result.

Interestingly, whole-embryo culture of caspase- $8^{D E D / D E D}$ embryos also resulted in normalization of neural tube formation, as neural tube kinks disappeared upon wholeembryo culture (Figure 5A). Normal development of the neural tube of the caspase- $8^{D E D / D E D}$ embryo was confirmed by histological observation (Figure 6A). Furthermore, no differences were detectable in the expression patterns of neurogenic and neuronal markers between wild-type and caspase- $8^{D E D / D E D}$ embryos by in situ hybridization analysis (Figure 6C). Expression of both neurogenic (Mash1 and Neurogenin-2) and neuronal (En1 and Evx1) markers was 

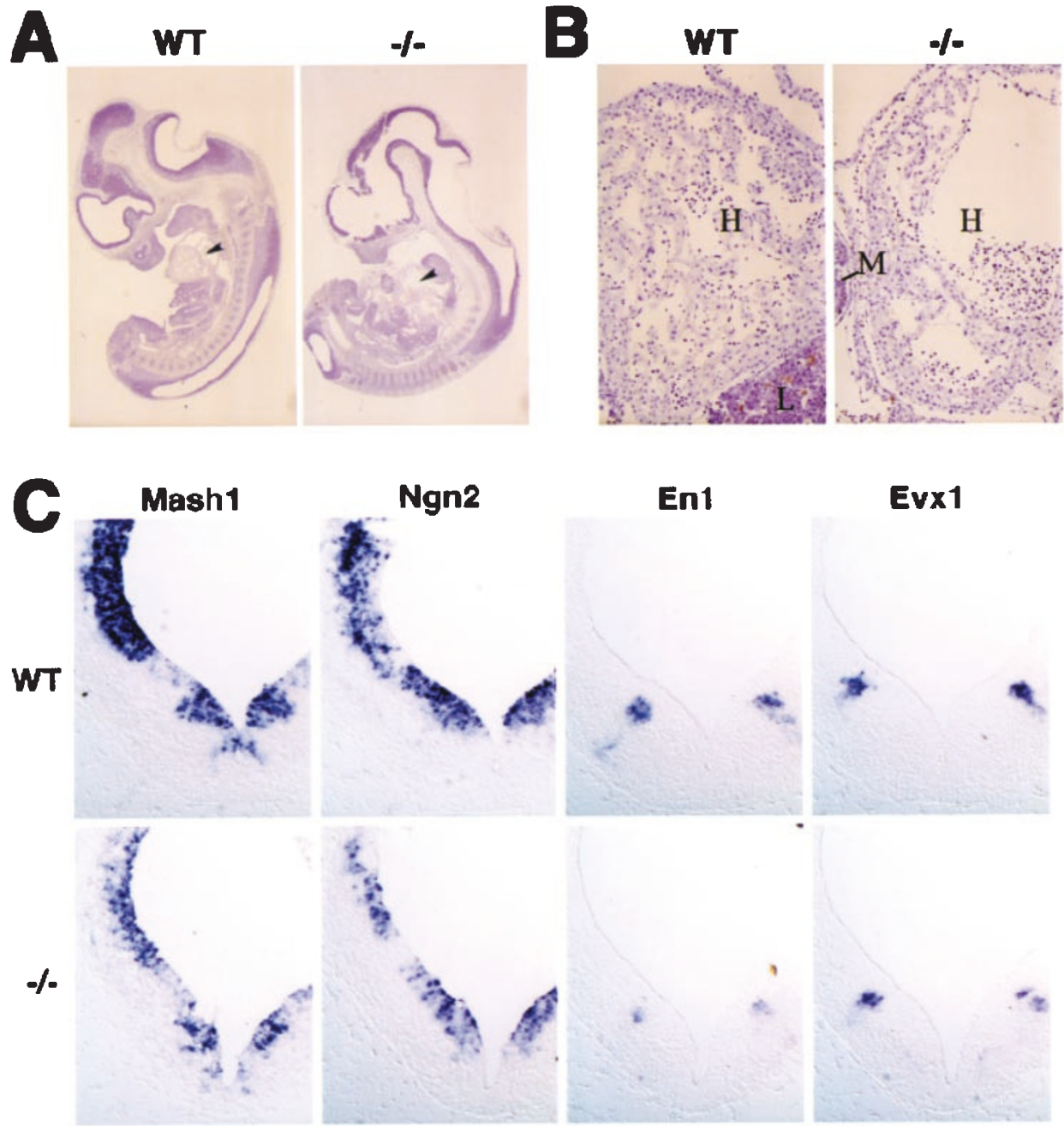

Figure 6 Recovery of caspase-8-deficient embryos by ex vivo whole-embryo culture. (A) Histology of wild-type (left) and caspase- $8^{D E D / D E D}$ (right) embryos cultured during E10.5-E11.5. Sagittal sections of embryos (45-50 somites) grown up from E10.5 embryos (34-38 somites) during culture were stained with hematoxylin and eosin. The hearts are indicated by arrowheads. (B) TUNEL staining of hearts from wild-type (left) and caspase- $8^{D E D / D E D}$ (right) embryos after whole-embryo culture. TUNEL-positive cells (colored brown) were not detected in the heart, but were detected in other tissues such as liver and midgut of both wildtype and caspase- $8^{D E D / D E D}$ embryos. (C) In situ hybridization of neural tubes from wild-type (top) and caspase-8 $8^{D E D / D E D}$ (bottom) embryos after culture. Transverse sections of hindbrain tube were examined with RNA probes for Mash1, Neurogenin-2 (Ngn2), En1 and Evx1. Abbreviations: WT, wild-type; -/-, caspase-8 $8^{D E D / D E D} ; \mathrm{H}$, heart; L, liver; M, midgut

detected in mutant as well as wild-type embryos. Thus, both major defects could be rescued by whole-embryo culture.

\section{Discussion}

In this study, we generated caspase-8-deficient mice devoid of proteolytic function, but expressing the DED domains of caspase-8, by targeted disruption using homologous recombination. Homozygous caspase- $8^{D E D / D E D}$ mice display an inappropriate vascular system formed in the yolk sac and defects in the developing neural tube as well as heart and die at E11.5, clearly indicating for the first time that protease activity of caspase- 8 is necessary for angiogenesis in the yolk sac and organogenesis during embryonic development.
Importantly, these mutant phenotypes can be rescued by ex vivo whole-embryo culture. No cardiac rupture or neural tube kinks occurred during culture (Figure 5A and 6), clearly indicating that these abnormalities may not all represent direct effects of caspase-8 deficiency. This evidence contradicts a previous report describing the direct involvement of caspase-8, its adapter FADD and the inhibitor molecule Casper in cell growth and survival of the developing heart. ${ }^{25}$ In our current study, however, caspase-8 protease activity, which is required for induction of apoptosis in a variety of cells, was found to be absolutely necessary for tissue formation during embryonic development. Moreover, we found that homozygous caspase-8deficient ES cells are able to differentiate into cardiomyocytes in vitro, suggesting no requirement of caspase-8 for 
cell growth and differentiation (data not shown). One possible explanation for the aberrant phenotypes of the mutant mice is that a factor or factors released from cells which survive inappropriately due to failure of caspase-8mediated apoptosis are responsible for the irregular development of the heart and neural tube as a secondary effect. During whole-embryo culture, these harmful factors could be diluted in the culture medium. Therefore, we hypothesize that caspase-8 and FADD transmit a death signal used to eliminate unwanted cells and that Casper antagonizes this signal in order to effect the survival of cells required for heart development. The whole-embryo culture system will be a valuable tool for assessing this hypothesis and understanding the physiological significance of caspase-8-mediated apoptosis during development, as well as the causal relations of defects observed in our proteasedeficient caspase-8 mutant mice.

During development, the process of pruning is essential for the maturation of the vascular system. The term is used to describe the loss of excess endothelial cells generated during vasculogenesis, resulting in a tree-like pattern of vasculature typical of normal angiogenesis. ${ }^{29}$ In this study, we have shown that this remodeling process is defective in the yolk sacs of caspase-8-deficient mice (Figure 3). Interestingly, this process was normal in the embryo proper. In addition, we confirmed by immunohistochemical analysis that vessels connecting the embryo proper and the yolk sac are normally developed and contain blood cells in caspase$8^{D E D / D E D}$ embryos (data not shown). Therefore, it seems that caspase-8 is essential for extraembryonic vascularization. By RT-PCR analysis, we were able to detect caspase-8 transcripts in the yolk sacs of wild-type embryos isolated at E10.5 and E11.5 (data not shown). Furthermore, it has been shown that programmed capillary regression is accompanied by apoptosis. ${ }^{30}$ These pieces of evidence suggest that pruning may be associated with caspasedependent apoptosis and that caspase- 8 is involved in this process.

Notch is an important molecule for controlling signal transduction and cell fate in vertebrate and invertebrate development. $^{31}$ Deficiency of Notch signaling influences organogenesis of many tissues. Interestingly, among the many defects resulting from disruption of the Notch signaling system, abnormalities of the heart, neural tube and yolk sac were observed which remarkably resemble those of our caspase-8-deficient mice. ${ }^{32-34}$ This would suggest a potential connection between caspase- 8 and the Notch signaling system. Further analysis, including an examination of the downstream molecules of the Notch signaling pathway in caspase-8-deficient mice, will be required in order to verify this potential connection.

We have demonstrated that caspase- 8 is essential during mid-stage mouse embryonic development. However, the fact that caspase- 8 was clearly observed in the thymus, skin and muscle of the wild-type E17 embryo (Figure 1) suggests that it may play an equally important role during the later stages of embryogenesis. Recent studies have shown that Fas transcripts are detectable in the developing thymus of E16.5 embryo, ${ }^{35}$ and that mouse thymocytes undergo apoptosis when treated with an agonistic anti-Fas antibody. ${ }^{36}$ In addition, deficiency of FADD resulted in abnormal development of thymocytes in the mutant mice. ${ }^{24}$ Because the activities of FADD, Fas and caspase- 8 are so closely intertwined, and because caspase-8 protein is present in the $\mathrm{E} 17$ thymus, it is reasonable, based on these findings, to predict an important functional role for caspase-8 in thymic development.

To understand the role of caspase- 8 in vivo, we and another group have generated caspase-8-deficient mice and shown that caspase-8 is involved in embryonic development. However, knowledge from these knockout mice is not sufficient to fully determine the physiological role of caspase-8 in embryogenesis. Consequently, these studies raise new questions, including how caspase- 8 is activated during development. As Fas-, TNFR1-, DR3DR6- and TRAIL-deficient embryos are viable, ${ }^{37-42}$ caspase-8 activation must occur in a manner independent of death receptors. Furthermore, it has been shown that both caspase-3- and Bid-deficient embryos displayed normal development of the heart, neural tube and yolk sac. ${ }^{18,43}$ As these molecules are both caspase-8-specific substrates, it seems reasonable to predict the existence of another target molecule recognized by caspase- 8 during embryogenesis. Clearly, the caspase-8-mediated signaling pathway, as it functions during embryonic development, requires further elucidation.

\section{Materials and Methods}

\section{Construction of the targeting vector and establishment of caspase-8 knockout mice}

A targeting vector was constructed for generating a truncated caspase-8 protein through introduction of a stop codon at exon 7 of the mouse caspase- 8 gene. ${ }^{26}$ In brief, a 1.2-kb EcoRI-Xbal fragment of the $5^{\prime}$ homologous region was ligated with the stop sequence, the polyadenylation signal derived from SV40 virus and a PGK-neo resistance gene expression cassette (PGKneobpA). ${ }^{44}$ Then, the 5-kb $B a m H I-E c o R I$ fragment from the $3^{\prime}$ homologous region containing exon 8 and the $\mathrm{MC} 1$-diphtheria toxin $\mathrm{A}$ fragment gene expression cassette (DT-A) ${ }^{45}$ were fused at the $3^{\prime}$ end of the vector. The targeting vector was linearized and introduced into R1 ES cells ${ }^{46}$ by electroporation. After screening by G418 selection at $180 \mu \mathrm{g} / \mathrm{ml}$ for 7-10 days, four recombinants were identified from 500 ES clones by PCR analysis and confirmed by Southern blot analysis with a $5^{\prime}$-probe (see Figure 2).

Chimeric mice were produced from two independent caspase$8^{D E D /+}$ ES clones by the aggregation method ${ }^{46}$ using C57BL/6 8-cellstage eggs and subsequent implantation into CD1 foster mothers. ${ }^{47}$ The resulting chimeric males were mated with $\mathrm{C} 57 \mathrm{BL} / 6$ females (SLC, Japan). Germline transmission of the mutant allele was verified by PCR and Southern blot analyses of tail DNA from offspring of C57BL/6 genetic background. The genotypes of embryos obtained by crossmating the heterozygous caspase- $8^{D E D /+}$ mice were also confirmed by PCR and Southern blot analyses.

\section{Southern blot analysis}

Genomic DNAs isolated from ES clones were digested with the restriction enzyme $\mathrm{BamHI}$, electrophoresed through a $0.7 \%$ agarose 
gel and transferred to nylon membranes (Hybond-N, Amersham Biosciences). Hybridization was performed as previously described ${ }^{48}$ using $\left[{ }^{32} \mathrm{P}\right]$-labeled DNA probes made with a Ready-to-Go DNA labeling kit (Amersham Biosciences).

\section{PCR and RT-PCR analyses}

PCR amplification for screening of ES clones and for genotyping of embryonic fibroblasts, embryos and mice was performed with two pairs of primers: primer $\mathrm{P} 1$ ( $5^{\prime}$-CCGTATGTCTGAAGACAGCTACTGT$3^{\prime}$ from intron 6) and primer P2 (5'-CTCTATGGCTTCTGAGGCGGAAAG-3' from PGKneobpA) for detection of the targeted allele, and primer P3 (5'-ATGAGATCCTGTGCCTTCTTCCCG-3' from intron 6) and primer P4 (5'-GTCACCGTGGGATAGGATACAGCA-3' from exon 7) for the normal allele. PCR was carried out as follows: initial denaturation at $96^{\circ} \mathrm{C}$ for 3 min following by 40 cycles of $94^{\circ} \mathrm{C}$ for $1 \mathrm{~min}$, $67^{\circ} \mathrm{C}$ for $2 \mathrm{~min}, 72^{\circ} \mathrm{C}$ for $3 \mathrm{~min}$ and extension at $72^{\circ} \mathrm{C}$ for $10 \mathrm{~min}$.

For RT-PCR analysis, total RNAs $(3 \mu \mathrm{g})$ isolated from E10.5 embryos using Isogen (Nippongene, Japan) were used for first-strand cDNA synthesis with an oligo-dT primer on Ready-To-Go RT-PCR beads (Amersham Biosciences), according to the manufacturer's recommendations. First-strand $c D N A s$ were amplified with three sets of primers: primers P4 and P5 (5'-ATGGCGGAACTGTGTGACTCG-3' on exon 5) for detection of normal caspase-8 transcripts, primers $P 5$ and P6 (5'-ATGTTTCAGGTTCAGGGGGAGGTG-3' in the SV40 polyA region) for truncated caspase-8 transcripts, and primers $P 7 \quad\left(5^{\prime}\right.$ CCTGATTGTTGCTGCTGGTGTTGG-3') and P8 (5'-GTCACGAACAGCAAAGCGACCAAG-3') for mouse EF1 $\alpha$ transcripts as a standard control. PCR was performed under the conditions described above and PCR products were analyzed by $1 \%$ agarose gel electrophoresis.

\section{Establishment of stable transfectants and embryonic fibroblasts}

To establish transfectants stably-expressing mouse caspase-8, we used JB-6 cells, a human T lymphoma Jurkat cell variant that is caspase-8-deficient. ${ }^{49}$ We transfected mouse caspase-8 cDNA with the neo resistance gene into this variant and selected them in $1.5 \mathrm{mg} /$ $\mathrm{ml}$ of G418. An established JB-6 stable clone and parental JB-6 cells were maintained in RPMI-1640 with $10 \%$ fetal calf serum. MEF cells were established from E10.5 embryos and their genotype was determined by PCR. These cells were maintained in D-MEM with $10 \%$ fetal calf serum.

\section{Immunoblot analysis}

For preparation of cell lysates, stable transfectants expressing mouse caspase- 8 and MEF cells were lysed in lysis buffer $(150 \mathrm{mM} \mathrm{NaCl}$, $0.1 \%$ Triton X-100, $10 \%$ glycerol, $1 \%$ EDTA, a cocktail of protease inhibitors and $20 \mathrm{mM}$ Tris- $\mathrm{HCl} \mathrm{pH} \mathrm{7.5).} \mathrm{Similarly,} \mathrm{cell} \mathrm{lysates} \mathrm{from} \mathrm{E8.5}$ embryos and from several E17 embryonic tissues were prepared after homogenization in the lysis buffer. These lysates were then analyzed by SDS - PAGE followed by immunoblotting with anti-mouse caspase8 and anti-actin (Chemicon) monoclonal antibodies. Prior to immunoblotting, the membrane transferred with cell lysates of MEF cells was immersed in phosphate-buffered saline (PBS) containing $3 \%$ formaldehyde for $10 \mathrm{~min}$. Then, immunoblot analysis was performed as described previously. ${ }^{50}$ An anti-mouse caspase- 8 monoclonal antibody was generated against full-length of mouse caspase- 8 produced in $E$. coli and recognizes the DED domain of caspase-8 (Kazama et al., unpublished data).

\section{Ex vivo whole-embryo culture}

For whole-embryo culture, embryos (34-38 somites) were dissected at E10.5 from pregnant mice after heterozygous mating. Cultivation of embryos was carried out at $37^{\circ} \mathrm{C}$ for $24 \mathrm{~h}$ in rat serum containing $2 \mathrm{mg} / \mathrm{ml}$ glucose as described. ${ }^{28}$ After culture, embryos (45-50 somites) were fixed in $4 \%$ paraformaldehyde (PFA) in PBS overnight for histology, immunohistochemistry and in situ hybridization. Genomic DNAs for genotyping were prepared from yolk sacs after culture.

\section{In situ hybridization}

Embryos were dissected at E10.5 and E11.5 and after whole-embryo culture, and fixed with 4\% PFA in PBS overnight. Frozen sections were cut on a cryostat and hybridization was performed as previously described. ${ }^{51}$ RNA probes for mouse Islet-2 (a gift from Dr. S Pfaff), Chox-10 (a gift from Dr. R Maclnnes), En1, Evx1 (gifts from Dr. M Goulding), Mash1 and Neurogenin-2 (gifts from Dr. F Guilmot) were prepared for hybridization.

\section{Histological analysis and TUNEL staining}

For histological analysis, embryos and yolk sacs were dissected at E10.5 and E11.5 and after whole-embryo culture, fixed in neutral formalin solution ( $\mathrm{pH} 7.4$ ), embedded in paraffin, and cut into $3.5 \mu \mathrm{m}$ sections for hematoxylin and eosin staining. For in situ demonstration of apoptosis, TUNEL staining was performed according to the manufacturer's instructions (Wako, Japan). After labeling, samples were counter-stained with hematoxylin.

\section{Immunohistochemical analysis}

Frozen sections from E10.5 and E11.5 embryos were immunostained essentially as described ${ }^{51}$ using anti- $\beta$-tubulin antibody (Sigma), antineurofilament antibody (2H3, Developmental Biology Hybridoma Bank), anti-Pax6 antibody ${ }^{52}$ and anti-Islet-1 antibody (40.2D6, Developmental Biology Hybridoma Bank). Detection of immunoreactivity was performed using an ABC kit (Vector Laboratories).

\section{Whole-mount immunohistochemistry}

Whole-mount immunohistochemistry was performed as previously described. ${ }^{53}$ Briefly, embryos dissected at E10.5 and yolk sacs prepared at E9.5, E10.5 and E11.5 were fixed in PBS containing $2 \%$ PFA for $2 \mathrm{~h}$ at $4^{\circ} \mathrm{C}$, immersed in cold PBS overnight and treated with PBS containing $0.15 \% \mathrm{H}_{2} \mathrm{O}_{2}$ and $0.1 \% \mathrm{NaN}_{3}$ at $4{ }^{\circ} \mathrm{C}$ for $1 \mathrm{~h}$. After washing with $\mathrm{PBS}$, embryos and yolk sacs were preincubated in blocking solution (PBS-MBT) containing $2 \%$ milk, $0.2 \%$ bovine serum albumin, $0.6 \%$ goat serum and $0.1 \%$ Triton $X-100$ at $4{ }^{\circ} \mathrm{C}$ for $1 \mathrm{~h}$. Then, the samples were incubated with a rat monoclonal anti-PECAM-1 antibody (BD-PharMingen) in PBS - MBT at $4{ }^{\circ} \mathrm{C}$ overnight and washed five times, $1 \mathrm{~h}$ each, with PBS-MT containing $2 \%$ milk and $0.1 \%$ Triton X-100 at room temperature. Subsequently, they were incubated with horseradish peroxidase-conjugated goat anti-rat $\operatorname{lgG}$ antibody (Cappel) in PBS - MBT at $4^{\circ} \mathrm{C}$ overnight, washed five times with PBSMT, and developed with PBS containing $0.1 \%$ Triton X-100, $0.03 \%$ $3,3^{\prime}$-diaminobenzidine and $0.08 \% \mathrm{NiCl}$. After washing with PBS, embryos were destained with a mixture of benzyl alcohol and benzyl benzoate. 


\section{Acknowledgements}

The authors would like to thank Drs. S Nagata, A Nagy and T Yagi for their gifts of JB-6 cells, RI cells and diphtheria toxin expression vector, Drs. R Kageyama, M Nozaki, K Koshimizu and $\mathrm{H}$ Yoshida for their valuable comments, and Ms. J Asami for excellent technical assistance. This work was supported in part by a Grant-in-Aid (12215070) from the Ministry of Education, Culture, Sports, Science and Technology of Japan to K Sakamaki.

\section{References}

1. Raff MC (1992) Social controls on cell survival and cell death. Nature $356: 397$ 400

2. Jacobson MD, Weil M and Raff MC (1997) Programmed cell death in animal development. Cell 88: $347-354$

3. Vaux DL and Korsmeyer SJ (1999) Cell death in development. Cell 96:245-254

4. Abbas AK (1996) Die and let live: eliminating dangerous lymphocytes. Cell 84 $655-657$

5. Thornberry NA and Lazebnik Y (1998) Caspases: enemies within. Science 281: $1312-1316$

6. Boldin MP, Goncharov TM, Goltsev YV and Wallach D (1996) Involvement of $\mathrm{MACH}$, a novel MORT1/FADD-interacting protease, in Fas/APO-1- and TNF receptor-induced cell death. Cell 85: $803-815$

7. Muzio M, Chinnaiyan AM, KischkelFC, O’Rourke K, Shevchenko A, Ni J, Scaffidi C, Bretz JD, Zhang M, Gentz R, Mann M, Krammer PH, Peter ME and Dixit VM (1996) FLICE a novel FADD-homologous ICE/CED-3-like protease, is recruited to the CD95 (Fas/APO-1) death-inducing signaling complex. Cell 85: 817-827

8. Ashkenazi A and Dixit VM (1998) Death receptors: signaling and modulation. Science 281: 1305-1308

9. Scaffidi C, Fulda S, Srinivasan A, Friesen C, Li F, Tomaselli KJ, Debatin KM Krammer PH and Peter ME (1998) Two CD95 (APO-1/Fas) signaling pathways. EMBO J. 17: 1675-1687

10. Scaffidi C, Medema JP, Krammer PH and Peter ME (1997) FLICE is predominantly expressed as two functionally active isoforms, caspase-8/a and caspase-8/b. J. Biol. Chem. 272: 26953-26958

11. Luo X, Budihardjol, Zou H, Slaughter C and Wang X (1998)Bid, a Bcl2 interacting protein, mediates cytochrome $\mathrm{c}$ release from mitochondria in response to activation of cell surface death receptors. Cell 94: 481-490

12. Varfolomeev EE, Schuchmann M, Luria V, Chiannilkulchai N, Beckmann JS, Mett IL, Rebrikov D, Brodianski VM, Kemper OC, Kollet O, Lapidot T, Soffer D, Sobe T, Avraham KB, Goncharov T, Holtmann H, Lonai P and Wallach D (1998) Targeted disruption of the mouse Caspase 8 gene ablates cell death induction by the TNF receptors, Fas/Apo1, andDR3 and is lethal prenatally. Immunity 9:267276

13. Bodmer JL, Holler N, Reynard S, Vinciguerra P, Schneider P, Juo P, Blenis J and Tschopp J (2000) TRAIL receptor-2 signals apoptosis through FADD and caspase-8. Nat. Cell Biol. 2: 241-243

14. Kischkel FC, Lawrence DA, Chuntharapai A, Schow P, Kim KJ and Ashkenazi A (2000) Apo2L/TRAIL-dependent recruitment of endogenous FADD and caspase- 8 to death receptors 4 and 5 . Immunity 12: 611-620

15. Sprick MR, Weigand MA, Rieser E, Rauch CT, Juo P, Blenis J, Krammer PH and Walczak H (2000) FADD/MORT1 and caspase-8 are recruited to TRAIL receptors 1 and 2 and are essential for apoptosis mediated by TRAIL receptor 2 . Immunity 12: 599-609

16. Los M, Wesselborg S and Schulze-Osthoff K (1999) The role of caspases in development, immunity, and apoptotic signal transduction: lessons from knockout mice. Immunity 10: 629-639

17. Zheng TS and Flavell RA (2000) Divinations and surprises: genetic analysis of caspase function in mice. Exp. Cell Res. 256: 67-73

18. Kuida K, Zheng TS, Na S, Kuan C, Yang D, Karasuyama H, Rakic P and Flavell RA (1996) Decreased apoptosis in the brain and premature lethality in CPP32deficient mice. Nature 384: 368-372

19. Kuida K, HaydarTF, Kuan CY, GuY, Taya C, Karasuyama H, Su MS, Rakic P and Flavell RA (1998) Reduced apoptosis and cytochrome c-mediated caspase activation in mice lacking caspase 9. Cell 94: 325-337
20. Hakem R, Hakem A, Duncan GS, Henderson JT, Woo M, Soengas MS, Elia A, de la Pompa JL, Kagi D, Khoo W, Potter J, Yoshida R, Kaufman SA, Lowe SW, Penninger JM and Mak TW (1998) Differential requirement for caspase 9 in apoptotic pathways in vivo. Cell 94: $339-352$

21. Cecconi F, Alvarez-Bolado G, Meyer BI, Roth KA and Gruss P (1998) Apaf1 (CED-4 homolog) regulates programmed cell death in mammalian development. Cell 94: 727-737

22. Yoshida H, Kong YY, Yoshida R, Elia AJ, Hakem A, Hakem R, Penninger JM and Mak TW (1998) Apaf1 is required for mitochondrial pathways of apoptosis and brain development. Cell 94: 739-750

23. Yeh WC, Pompa JL, McCurrach ME, Shu HB, Elia AJ, Shahinian A, Ng M Wakeham A, Khoo W, Mitchell K, El-Deiry WS, Lowe SW, Goeddel DV and Mak TW (1998) FADD: essential for embryo development and signaling from some, but not all, inducers of apoptosis. Science 279: 1954-1958

24. Zhang J, Cado D, Chen A, Kabra NH and Winoto A (1998) Fas-mediated apoptosis and activation-induced T-cell proliferation are defective in mice lacking FADD/Mort1. Nature 392: 296-300

25. Yeh WC, Itie A, Elia AJ, Ng M, Shu HB, Wakeham A, Mirtsos C, Suzuki N Bonnard M, Goeddel DV and Mak TW (2000) Requirement for Casper (c-FLIP) in regulation of death receptor-induced apoptosis and embryonic development. Immunity 12: 633-642

26. Sakamaki K, Tsukumo S and Yonehara S (1998) Molecular cloning and characterization of mouse caspase-8. Eur. J. Biochem. 253: 399-405

27. Vincenz C and Dixit VM (1997) Fas-associated death domain protein interleukin1beta-converting enzyme 2 (FLICE2), an ICE/Ced-3 homologue, is proximally involved in CD95- and p55-mediated death signaling. J. Biol. Chem. 272: 6578 6583

28. Osumi-Yamashita N, Ninomiya $Y$ and Eto K (1997) Mammalian craniofacial embryology in vitro. Int. J. Dev. Biol. 41: 187-194

29. Risau W (1997) Mechanisms of angiogenesis. Nature 386: 671-674

30. Meeson AP, Argilla M, Ko K, Witte L and Lang RA (1999) VEGF deprivationinduced apoptosis is a component of programmed capillary regression. Development 126: 1407-1415

31. Artavanis-Tsakonas S, Rand MD and Lake RJ (1999) Notch signaling: cell fate control and signal integration in development. Science 284: 770-776

32. Krebs LT, Xue Y, Norton CR, Shutter JR, Maguire M, Sundberg JP, Gallahan D, Closson V, Kitajewski J, Callahan R, Smith GH, Stark KL and Gridley T (2000) Notch signaling is essential for vascular morphogenesis in mice. Genes Dev. 14: 1343-1352

33. Huppert SS, Le A, Schroeter EH, Mumm JS, Saxena MT, Milner LA and Kopan R (2000) Embryonic lethality in mice homozygous for a processing-deficient allele of Notch1. Nature 405: $966-970$

34. Rones MS, McLaughlin KA, Raffin M and Mercola M (2000) Serrate and Notch specify cell fates in the heart field by suppressing cardiomyogenesis. Development 127: 3865-3876

35. French LE, Hahne M, Viard I, Radlgruber G, Zanone R, Becker K, Muller C and Tschopp J (1996) Fas and Fas ligand in embryos and adult mice: ligand expression in several immune-privileged tissues and coexpression in adult tissues characterized by apoptotic cell turnover. J. Cell Biol. 133: 335-343

36. Nishimura-Morita Y, Nose M, Inoue T and Yonehara S (1997) Amelioration of systemic autoimmune disease by the stimulation of apoptosis-promoting receptor Fas with anti-Fas mAb. Int. Immunol. 9: 1793-1799

37. Adachi M, Suematsu S, Kondo T, Ogasawara J, Tanaka T, Yoshida N and Nagata S (1995) Targeted mutation in the Fas gene causes hyperplasia in peripheral lymphoid organs and liver. Nat. Genet. 11: 294-300

38. Pfeffer K, Matsuyama T, Kundig TM, Wakeham A, Kishihara K, Shahinian A Wiegmann K, Ohashi PS, Kronke M and Mak TW (1993) Mice deficient for the $55 \mathrm{kd}$ tumor necrosis factor receptor are resistant to endotoxic shock, yet succumb to L. monocytogenes infection. Cell 73: 457-467

39. Rothe J, Lesslauer W, Lotscher H, Lang Y, Koebel P, Kontgen F, Althage A Zinkernagel R, Steinmetz M and Bluethmann H (1993) Mice lacking the tumour necrosis factor receptor 1 are resistant to TNF- mediated toxicity but highly susceptible to infection by Listeria monocytogenes. Nature 364: 798-802

40. Wang EC, Thern A, Denzel A, Kitson A, Farrow SN and Owen MJ (2001) DR3 regulates negative selection during thymocyte development. Mol. Cell. Biol. 21: $3451-3461$ 
41. Liu J, Na S, GlasebrookA, Fox N, Solenberg PJ, Zhang Q, Song HY and Yang DD (2001) Enhanced CD4 ${ }^{+}$T cell proliferation and Th2 cytokine production in DR6deficeint mice. Immunity 15: 23-34

42. Cretney E, Takeda K, Yagita H, Glaccum M, Peschon JJ and Smyth MJ (2002) Increased susceptibility to tumor initiation and metastasis in TNF-related apoptosis-inducing ligand-deficient mice. J. Immunol. 168: 1356-1361

43. Yin XM, Wang K, Gross A, Zhao Y, Zinkel S, KlockeB, Roth KA and Korsmeyer SJ (1999) Bid-deficient mice are resistant to Fas-induced hepatocellular apoptosis. Nature 400: 886-891

44. Soriano P, Montgomery C, Geske R and Bradley A (1991) Targeted disruption of the c-src proto-oncogene leads to osteopetrosis in mice. Cell 64: 693-702

45. Yagi T, Nada S, Watanabe N, Tamemoto H, Kohmura N, Ikawa Y and Aizawa S (1993) A novel negative selection for homologous recombinants using diphtheria toxin A fragment gene. Anal. Biochem. 214: 77-86

46. Nagy A, Rossant J, Nagy R, Abramow-Newerly W and Roder J (1993) Derivation of completely cell culture-derived mice from early-passage embryonic stem cells. Proc. Natl. Acad. Sci. USA 90: 8424-8428

47. Asano M, Furukawa K, Kido M, Matsumoto S, Umesaki Y, Kochibe N and Iwakura Y (1997) Growth retardation and early death of beta-1, 4-galactosyltransferase knockout mice with augmented proliferation and abnormal differentiation of epithelial cells. EMBO J. 16: 1850-1857
48. SakamakiK, Tomonaga M, Tsukui Kand Nagata S (1989) Molecular cloning and characterization of a chromosomal gene for human eosinophil peroxidase. J. Biol. Chem. 264: 16828-16836

49. Kawahara A, Ohsawa Y, Matsumura H, Uchiyama $Y$ and Nagata S (1998) Caspase-independent cell killing by Fas-associated protein with death domain. J. Cell. Biol. 143: 1353-1360

50. Sakamaki K, Wang H-M, Miyajima I, Kitamura T, Todokoro K, Harada N and Miyajima A (1993) Ligand-dependent activation of chimeric receptors with the cytoplasmic domain of the interleukin-3 receptor $\beta$ subunit $\left(\beta_{\mathrm{IL} 3}\right)$. J. Biol. Chem. 268: $15833-15839$

51. Osumi N, Hirota A, Ohuchi H, Nakafuku M, limura T, Kuratani S, Fujiwara M, Noji $S$ and Eto K (1997) Pax-6 is involved in the specification of hindbrain motor neuron subtype. Development 124: 2961-2972

52. Inoue T, Nakamura $S$ and Osumi N (2000) Fate mapping of the mouse prosencephalic neural plate. Dev. Biol. 219: 373-383

53. Yoshida H, Kunisada T, Kusakabe M, Nishikawa S and Nishikawa S-I (1996) Distinct stages of melanocyte differentiation revealed by analysis of nonuniform pigmentation patterns. Development 122: 1207-1214 